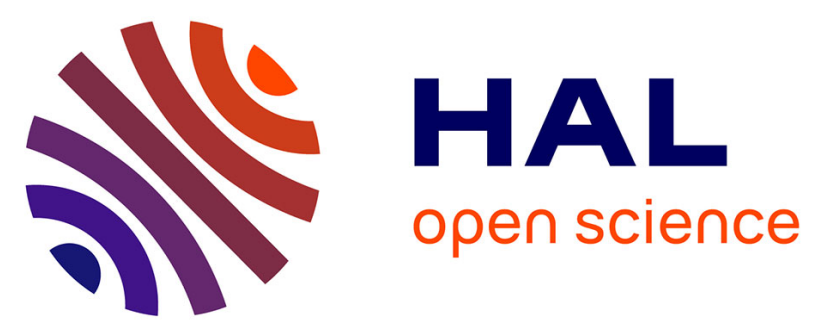

\title{
Shear flows accelerate mixing dynamics in hyporheic zones and hillslopes
}

\author{
Aditya Bandopadhyay, Philippe Davy, Tanguy Le Borgne
}

\section{To cite this version:}

Aditya Bandopadhyay, Philippe Davy, Tanguy Le Borgne. Shear flows accelerate mixing dynamics in hyporheic zones and hillslopes. Geophysical Research Letters, 2018, 45 (21), pp.11659-11668. 10.1029/2018GL079914 . insu-01901766

\section{HAL Id: insu-01901766 https://hal-insu.archives-ouvertes.fr/insu-01901766}

Submitted on 16 Jan 2019

HAL is a multi-disciplinary open access archive for the deposit and dissemination of scientific research documents, whether they are published or not. The documents may come from teaching and research institutions in France or abroad, or from public or private research centers.
L'archive ouverte pluridisciplinaire HAL, est destinée au dépôt et à la diffusion de documents scientifiques de niveau recherche, publiés ou non, émanant des établissements d'enseignement et de recherche français ou étrangers, des laboratoires publics ou privés. 


\section{Geophysical Research Letters}

\section{RESEARCH LETTER \\ 10.1029/2018GL079914 \\ Shear Flows Accelerate Mixing Dynamics in Hyporheic Zones and Hillslopes}

Key Points:

- Hydraulic head gradients induced by bedforms and hillslopes generate shear flows in the subsurface

- Shear flows accelerate transient mixing rates in flow cells and trigger transient mixing hot spots

- Estimates of shear rates for hyporheic zones, hillslopes, and catchments vary over orders of magnitude

Supporting Information:

- Supporting Information S1

Correspondence to:

T. Le Borgne,

tanguy.le-borgne@univ-rennes1.fr

Citation:

Bandopadhyay, A., Davy, P., \& Le Borgne, T. (2018). Shear flows accelerate mixing dynamics in hyporheic zones and hillslopes. Geophysical Research Letters, 45, 11,659-11,668. https://doi.org/10.1029/2018GL079914

Received 8 AUG 2018 Accepted 28 SEP 2018 Accepted article online 5 OCT 2018 Published online 4 NOV 2018 into the patterns and dynamics of mixing at hyporheic zone, hillslope, and catchment scales. context of surface water-groundwater interactions.

\author{
Aditya Bandopadhyay ${ }^{1}$, Philippe Davy² ${ }^{2}$, and Tanguy Le Borgne ${ }^{2}$ \\ ${ }^{1}$ Department of Mechanical Engineering, Indian Institute of Technology Kharagpur, Kharagpur, India, ${ }^{2}$ Université de \\ Rennes 1, CNRS, Géosciences Rennes UMR 6118, Rennes, France
}

Abstract Topographic relief and river bedforms generate nested streamline patterns, which drive the propagation and mixing at depth of changes in surface water concentration or temperature. While concentration distributions and biogeochemical reactions in such flow cells are often studied under steady state transport conditions, there is increasing evidence that transient mixing processes may have a significant contribution to effective mixing and reaction rates. Here we show that these streamline patterns act as shear flows, which significantly accelerate mixing dynamics within flow cells and can lead to the formation of transient mixing hot spots at depth. We provide analytical solutions that quantify the dynamics of mixing in a flow cell for a pulse and a front initial solute distribution, which represent two idealized end-members of more complex solute distributions in natural systems. These results provide new insights

Plain Language Summary As surface water infiltrates in the subsurface in riverbeds or hillslopes, it mixes with the resident groundwater, which leads to changes in the concentration of transported dissolved chemical species. Such transient mixing processes play a key role in contaminant transport and biogeochemical reactions. Here we demonstrate that flow patterns that are generated by topography gradients at different scales act effectively as shear flows due to the differential velocity of neighboring streamlines. We show that such shear flows strongly enhance transient mixing rates and may lead to the formation mixing hot spots where mixing rates are orders of magnitude larger than the background. These results will likely contribute to the understanding and modeling of solute transport and reaction in the

\section{Introduction}

The Earth's topography, from river bedforms to hillslopes, exerts a basic control on hydraulic head gradients driving flow, transport and reactions in the subsurface, recharge-discharge patterns, and interactions between surface and subsurface water (Figure 1) bodies (Brunner et al., 2017; Freeze \& Witherspoon, 1966, 1967; Toth, 1963). At catchment scale, groundwater circulation follows nested patterns of local and regional flow lines dictated by the distribution of hydraulic head gradients (Cardenas, 2007), hence determining the distribution and kinetics of processes such as mineral dissolution, precipitation, redox reactions, and ore formation (Li et al., 2017; Maher \& Chamberlain, 2014; Reeve et al., 2000; Tóth, 2009; Vaccaro \& Bolke, 1983). At the hillslope scale, subsurface flow sets the travel time of dissolved species from surface infiltration to river discharge, while mixing determines their concentration signatures in the fluctuation signals observed in rivers (Kirchner et al., 2000; Kirchner \& Neal, 2013) and in concentration-discharge relationships (Godsey et al., 2009). In wetlands, microtopography variations can induce a zonation of infiltrating-exfiltrating flow paths leading to localized biogeochemical hot spots (Frei et al., 2012). At the riverbed scale, interactions between turbulence, hydraulic head gradients, and bed morphology drive fluxes, mixing rates, and biogeochemical processes in the hyporheic zone, as bedform topology influences significantly flow and reaction patterns (Boano et al., 2007; Briggs et al., 2015; Brunner et al., 2017; Cardenas, 2008; Elliott \& Brooks, 1997; Harvey \& Bencala, 1993; Holmes et al., 1996; Gomez-Velez et al., 2015; Savant et al., 1987; Trauth \& Fleckenstein, 2017; Trauth et al., 2014). Surface topography plays a significant role in all these systems. However, what matters ultimately is the topography of the hydraulic head field. In what follows, we shall refer to such flows as topography-driven flows for brevity. 
(a)
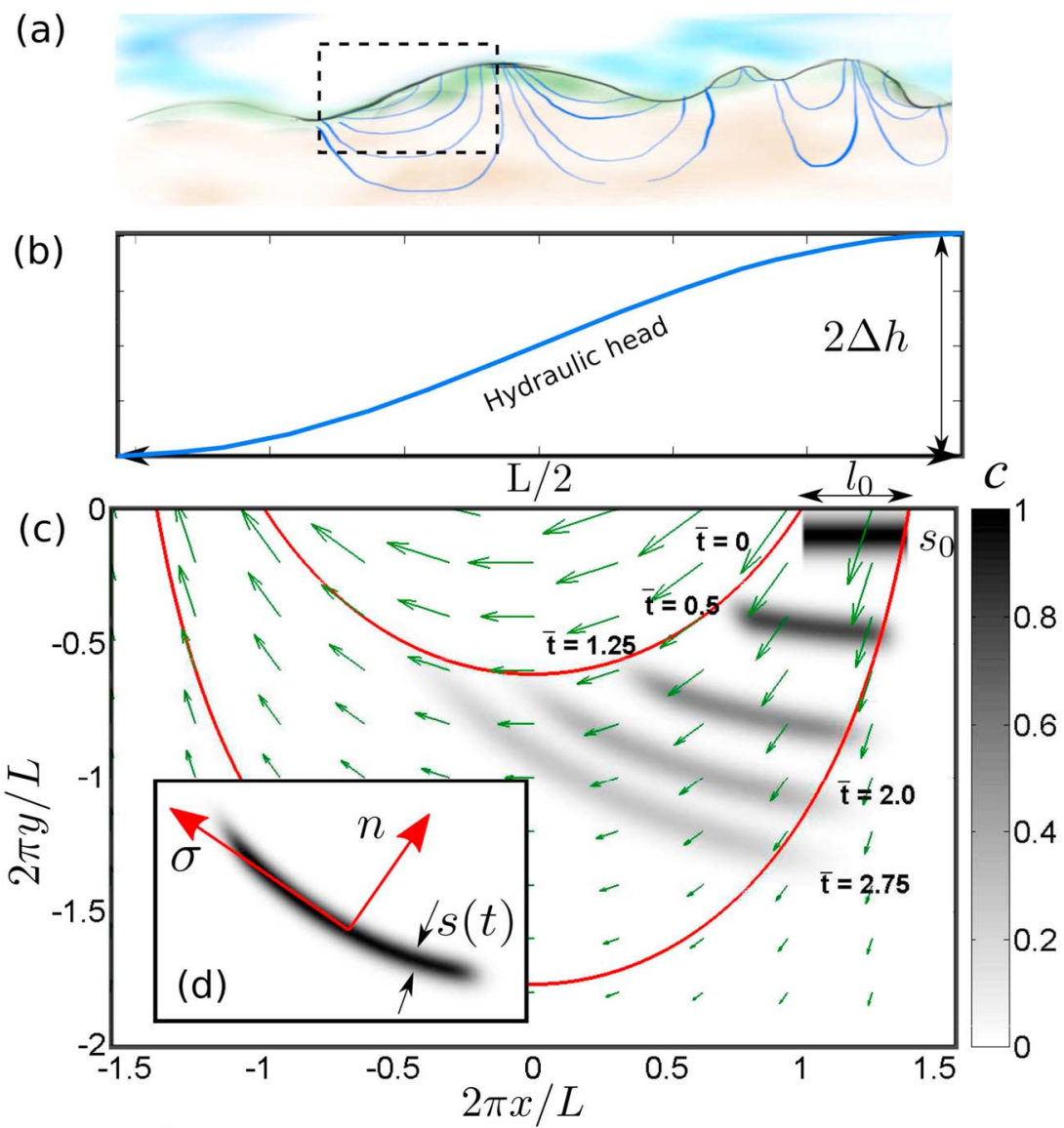

(e)

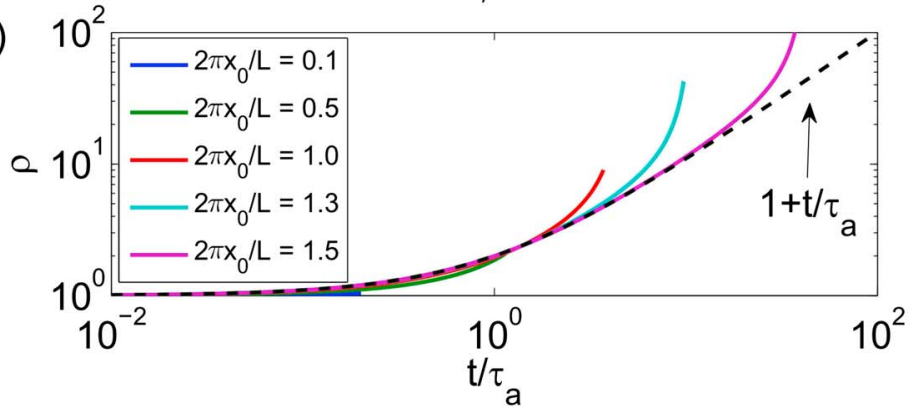

Figure 1. (a)Topography driven flows in the subsurface.The dotted section depicts (b) the magnified portion idealized as a sinusoidal hydraulic head. The mirror symmetric domain spans over $(x, y) \in[-L / 4, L / 4] \times[0,-\infty]$. (c) An initially uniform plume of vertical width $s_{0}$ containing a solute deforms into an elongated thin lamellar structure due to the differential velocity between the two representative streamlines (red lines). The plume is shown at different normalized times $\bar{t}=t / \tau_{a}$. The simulation is performed in a $500 \times 500$ grid domain for $P e=10^{3}$. (d) The coordinate system attached to the lamella has tangential, $\sigma$, and normal, $n$, directions. (e) Temporal elongation, $\rho$, of an element of the tracer line for various initial injection points. The dashed line represents an equivalent mean linear stretching given by $\rho=I(t) / I_{0}=1+t / \tau_{a}$.

Mixing processes in topography-driven flows are often studied by assuming steady state transport conditions (Bardini et al., 2012; Hester et al., 2014; Naranjo et al., 2015; Trauth et al., 2014). In this scenario, mixing occurs through transverse mixing across different flow cells (Cirpka et al., 2006; Rolle et al., 2009). Yet, as the relative difference between surface and subsurface hydraulic heads fluctuate in time, flow cells can expand and contract and new flow cells can form dynamically, for instance when switching from groundwater discharge to recharge conditions. This leads to transient mixing processes (Figure 1c), which can influence significantly overall mixing and reaction rates (Bartsch et al., 2014; Gu et al., 2012; Hester et al., 2017; Kaufman et al., 2017; Maier \& Howard, 2011; Malzone et al., 2016; Schmadel et al., 2016; Trauth \& Fleckenstein, 2017). While the impact of medium heterogeneity on such transient mixing and reaction dynamics has been intensively stud- 
ied (Chiogna et al., 2012; Cirpka \& Kitanidis, 2000; Engdahl et al., 2014; Green et al., 2010; Jiménez-Martínez et al., 2015; Kitanidis, 1994; Le Borgne et al., 2010; Le Borgne et al., 2015), the effect of nonuniform velocity fields induced by complex boundary conditions (e.g., topographic relief and nonuniform hydraulic head gradients) has received lesser attention. The nature of topography-driven flows is such that the velocity magnitude of the neighboring streamlines differ (Figure 1c), leading to a gradient of water age transverse to the direction of the flow. Furthermore, this differential velocity increases the area available for diffusive mass transfer of chemical species spanning across the streamlines, thus potentially enhancing mixing rates, solution dilution, and influencing the kinetics of associated biogeochemical reactions.

Here we analyze the impact of topography-driven streamlines on transient mixing dynamics in steady state flows (Figure 1c). We focus on the impact of streamline patterns on mixing of a solute plume, which may result from a newly infiltrating water with a chemistry that is different from the resident water or from a chemical zonation resulting from past flow conditions. We quantify both longitudinal mixing and transverse mixing across streamlines inside a flow cell while neglecting transverse mixing across different flow cells. We then employ a Lagrangian approach to predict the influence of velocity gradients and plume stretching on transient mixing dynamics. We demonstrate that topography-driven flows produce linear stretching in time, acting effectively as shear flows. We obtain analytical solutions for dissolved species distributions and mixing rates as a function of scale, hydrologic, and transport parameters. We discuss consequences of these findings regarding the impact of topography-driven hydraulic head gradients on the enhancement of mixing rates and the formation of transient mixing hot spots at hyporheic zone, hillslope, and catchment scales.

\section{Topography-Driven Shear Flows}

\subsection{Hydraulic Head Gradients and Subsurface Flow Streamlines}

Following Toth $(1963,2009)$, we study the influence of a sinusoidal imposed hydraulic head on subsurface streamlines distributions and its effect on mixing rates in a flow cell (Figure 1b). We consider a 2-D system with a sinusoidal imposed hydraulic head on the top surface of the semi-infinite domain,

$$
h(x, 0)=\Delta h \sin (2 \pi x / L)
$$

with a hydraulic head difference equal to $\Delta h$ and a characteristic length of the sinusoidal head equal to $L / 2 \pi$ (Figure 1b). The characteristic hydraulic head gradient is

$$
\overline{\nabla h}=2 \pi \Delta h / L
$$

For a uniform conductivity field, $K$, the steady state hydraulic head $h$ is given, through Darcy's law and flow conservation, by

$$
\nabla \cdot K \nabla h=0
$$

Equation (3) is subjected to the condition that

$$
\begin{aligned}
& \text { at } y=0, h=\Delta h \sin (2 \pi x / L) \\
& \text { as } y \rightarrow \infty, h=0 \\
& \text { at } x=-L / 4, L / 4 ; \partial h / d x=0 .
\end{aligned}
$$

This idealized situation has been utilized to analyze topography-driven flows over regional systems (Tóth, 2009) to hyporheic flows (Boano et al., 2007; Elliott \& Brooks, 1997; Eylers, 1994). Subsurface flow is induced by the gradient of head from a region of high hydraulic head to that of a lower hydraulic head. Assuming that time scales of flow cell formation are shorter than transport time scales, we study transient transport processes in steady flows. In section $\mathrm{S} 6$ of the supporting information we discuss the effect of more complex hydraulic head gradient patterns (e.g., see Jiang et al., 2011; Zlotnik et al., 2011) and of the presence of an impermeable layer at a given depth.

The solution to equation (3) is (Elliott \& Brooks, 1997; Toth, 1963)

$$
h(x, y)=\Delta h \exp (2 \pi y / L) \sin (2 \pi x / L)
$$




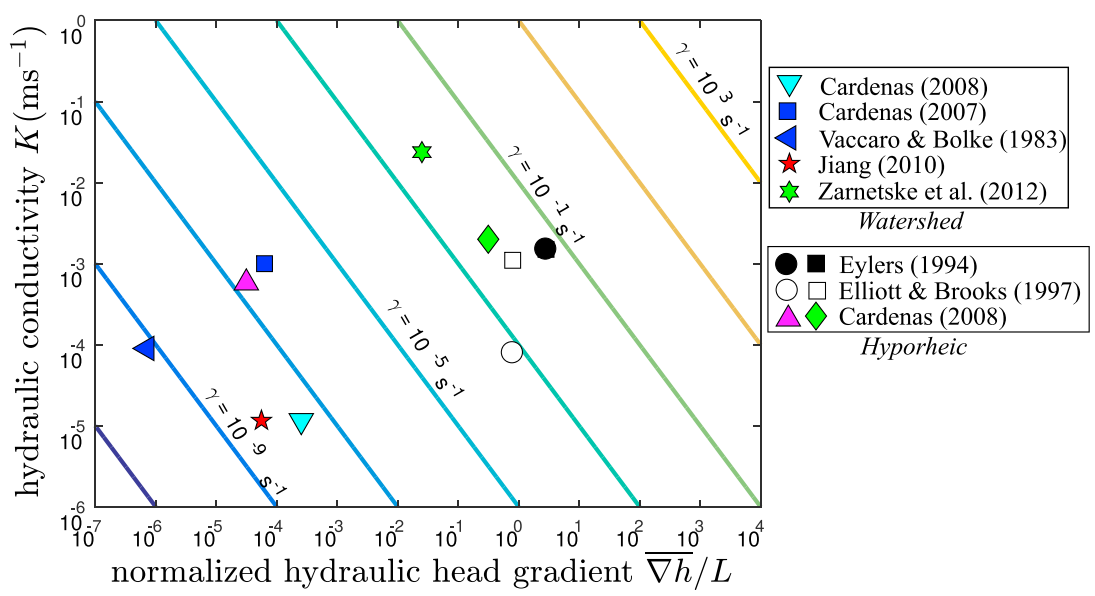

Figure 2. Isocontours of effective shear as a function of the conductivity and hydraulic head gradient $(K-\overline{\nabla h} / L$ space). Symbols correspond to shear rates estimated from equation (9) for experimental and synthetic studies of flow and transport in hyporheic and regional flows (Tables S1 and S2 in supporting information). The hyporheic zone data correspond to the scenario depicted in Elliott and Brooks (1997), Eylers (1994), and Cardenas (2008), while the watershed data correspond to Cardenas, (2007, 2008), Vaccaro and Bolke (1983), Jiang et al., 2010 (2010), and Zarnetske et al., 2012 (2012).

The corresponding velocity components $(u, v)$ are determined through Darcy's law as

$$
\begin{aligned}
& u(x, y)=-\frac{K}{\phi} \overline{\nabla h} \exp (2 \pi y / L) \cos (2 \pi x / L), \\
& v(x, y)=-\frac{K}{\phi} \overline{\nabla h} \exp (2 \pi y / L) \sin (2 \pi x / L),
\end{aligned}
$$

where $\phi$ is the porosity. The characteristic advection time is given by the characteristic length over the mean velocity:

$$
\tau_{a}=L \phi /(2 \pi K \overline{\nabla h})
$$

Velocity vectors and two representative streamlines are depicted in Figure 1c. The drainage divide, corresponding to location of maximum head, is located at $x_{0}=L / 4$. The streamline structures for sinusoidal head, square head, and sinusoidal head imposed on a linear head are depicted in Figure S3 in the supporting information. The influence of the lower bounding surface is depicted in Figure S2 for completeness.

\subsection{Deformation of Fluid Elements by Streamline Topology}

A fundamental driver for the enhancement of mixing in flows is fluid stretching, which increases the interface area between solutes that mix and react (de Anna, Jimenez-Martinez, et al., 2014; de Barros et al., 2012; Le Borgne et al., 2013, 2014). As illustrated in Figure 1c, a solute plume located initially at the surface is elongated by diverging streamlines and simultaneously compressed in the instantaneous normal direction, $n$, via incompressibility. Fluid deformation is quantified through the elongation $\rho=I / I_{0}$, where $I$ is the distance between two advective particles separated initially by a distance $I_{0}$ (section $S 1$ in supporting information and Ottino, 1989). For the case of a continuous injection, $\rho$ corresponds to the elongation of the front.

Figure 1e displays the elongation $\rho$ for different initial positions. For a range of times, the deformation is the same for all streamlines and follows closely the linear evolution:

$$
\rho=1+\gamma t
$$

with $\gamma=1 / \tau_{a}$. This algebraic increase is due to the shear induced by the differential alignment of the strip on the faster streamline relative to the slower streamline (Figure 1c). As fluid elements approach the outlet, their elongation deviates from the linear behaviour and increases more rapidly. This late increase is attributed to the acceleration of particles along streamlines near the outlet. Although the late-time deformation is significant, it acts over a short time, just before particles leave the domain (see section S5 and Figure S2 in supporting information). Hence, for particles in the domain, topography-driven flows act in an equivalent manner to a 
shear flow (Bandopadhyay et al., 2017; Paster et al., 2015) with an effective shear rate:

$$
\gamma=2 \pi K \overline{\nabla h} /(L \phi)
$$

As discussed in section $\mathrm{S} 6$ of supporting information the shear flow approximation also holds relatively well for complex hydraulic head topographies and in the presence of a lower impremeable layer. For a given hydraulic head gradient, the shear rate increases with the hydraulic conductivity and decreases with scale (equation (9)). As the hydraulic conductivity of the subsurface spans orders of magnitude, shear rates vary over a broad range, as illustrated from estimates obtained from different past studies at scales ranging from hyporheic zone to catchment scale (Figure 2; please refer to Cardenas, 2007, 2008; Jiang et al., 2010; Vaccaro \& Bolke, 1983; Zarnetske et al., 2012, for more details). Shear is generally larger for hyporheic flows than for catchment flows (see section S4 and Table S2 in supporting information).

\section{Mixing Dynamics}

To investigate the consequences of shear flows on transient mixing dynamics, we consider two idealized scenarios that represent end-members of more complex conditions occurring in natural systems. In the first case, the solute is initially distributed as a pulse close to the surface (Figure 1c). This case is of fundamental interest since more complex solute concentration histories at the surface can be simulated from a convolution with the solution for a pulse injection. The second case is that of a continuous injection of solute at the upstream boundary. This represents a full replacement of a flow cell with surface water that mixes with resident groundwater, as would occur, for instance, when switching from a discharge to a recharge situation. We solve the transient mixing dynamics within a single flow cell, including longitudinal mixing and transverse mixing across streamlines, while neglecting transverse mixing between different flow cells.

The pulse scenario is relevant to understand the fate of pulses of dissolved species, such as nutrients or contaminants, in river or recharge water. The initial plume may also result from a chemical zonation inherited from past flow conditions (Bardini et al., 2012). In natural systems, changes in surface species concentration rarely take the idealized form of the considered pulse or continuous injection. Solute concentrations in rivers may, for instance, vary periodically following diurnal or seasonal cycles. The consequences of shear flow on the propagation of such signals can be understood by convolution of the response to an instantaneous injection derived here with a sinusoidal input. The analysis of sinusoidal signal also finds importance for convective heat transfer in the hyporheic zone (Marzadri et al., 2013; Song et al., 2018; Zheng \& Cardenas, 2018) and at basin scale (Kooi, 2016). The latter is often approximated by analytical solutions that assume one-dimensional advection and diffusion, hence neglecting the effect of shear flows (Hatch et al., 2006; Stallman, 1965). Although the detailed study of sinusoidal signals is beyond the scope of the current study, we provide an illustration on the effect of shear on the attenuation of such signals in the supporting information (see section S7 and Figure S5 in supporting information ).

The replacement scenario is relevant to understand the dynamics of mixing in newly formed flow cells. Changes in the relative hydraulic head of surface and subsurface compartments can expand and contract flow cells, change the streamline patterns, or turn periodically a discharge zone into a recharge zone (Bartsch et al., 2014; Gu et al., 2012; Hester et al., 2017; Kaufman et al., 2017; Maier \& Howard, 2011; Malzone et al., 2016; Schmadel et al., 2016). In these cases, part or all of a flow cell may experience transient mixing dynamics, influenced by shear flow, until a new steady state is reached for transport. Mixing rates that occur during these transient states, whether they take place naturally or are induced by river management strategies such as hydropeaking, can be much larger than those occurring under steady transport conditions, hence possibly dominating the macroscopic system behavior (Trauth \& Fleckenstein, 2017).

To quantify the effect of shear on mixing and reaction, we use a Lagrangian method allowing derivation of explicit analytical expressions relating plume elongation to mixing and reaction rates. In this approach, the tracer plume is decomposed in an ensemble of elongated strips, called lamellae, that deform due to local velocity gradients. Since concentration gradients are much larger in the direction perpendicular to the lamella than along the lamella, the 2-D equations governing the transport can be reduced to 1-D equations depending on the Lagrangian coordinate $n$ (Figure 1d; supporting information de Anna, Dentz, et al., 2014; Le Borgne et al., 2013, 2014; Meunier \& Villermaux, 2010; Ranz, 1979). This method leads to analytical expressions for the spatial distribution of concentration and mixing rates across streamlines within a flow cell. The solute of initial concentration $c_{0}$, which may represent for instance dissolved oxygen, nitrate, 


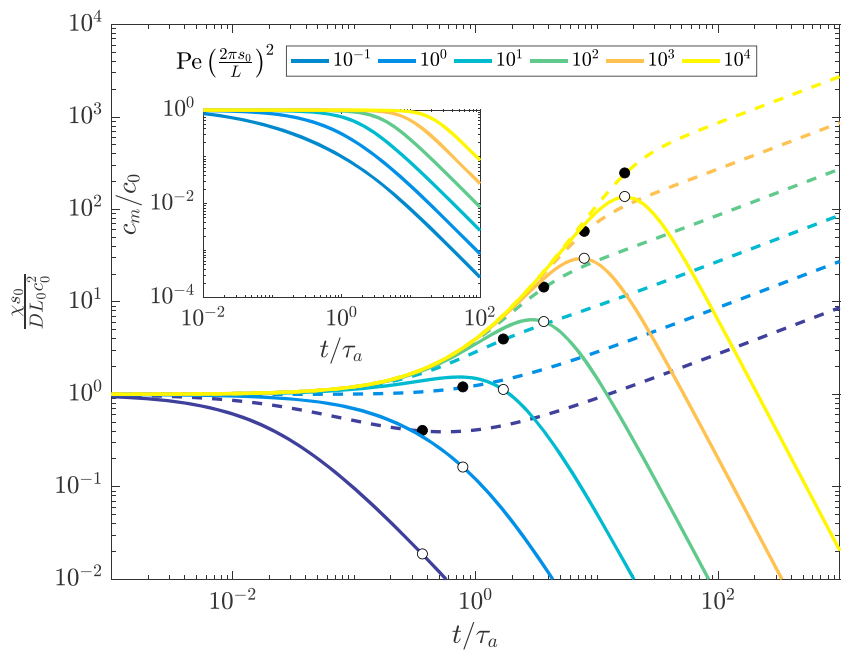

Figure 3. Temporal evolution of the dimensionless scalar dissipation rate $\chi /\left(D I_{0} c_{0}^{2} / s_{0}\right)$ along streamlines for the case of a pulse (continuous lines) and a continuous (dashed lines) conservative tracer injection. The inset depicts the temporal evolution of the maximum concentration for the case of a pulse injection. The black and white markers correspond to the dissipation rate at the mixing time for continuous and pulse injection, respectively. dissolved organic matter, or a dissolved contaminant, is injected over the length $I_{0}$ (Figure $1 \mathrm{c}$ ). For the pulse scenario, the initial width $s_{0}$ represents the depth of the initial plume. $I_{0} s_{0}$ is the initial volume of solute per unit length (this length corresponds to the direction perpendicular to the considered two-dimensional domain). For the replacement scenario, $s_{0}$ is the characteristic length over which concentration gradients are distributed before transport in the flow cell. These initial gradients may be inherited from a previous flow cell or formed diffusively before the initiation of flow in the cell.

The dispersion tensor $D$ is assumed to be isotropic and constant for analytical tractability. This assumption could be relaxed by considering an anisotropic dispersion tensor that depends on the local velocity. Indeed, in the considered scenario, mixing is expected to be controlled mainly by longitudinal mixing at early times and by transverse mixing at late times. We take an effective dispersion coefficient such as, $D=\alpha \bar{u}$, where $\bar{u}=L / \tau_{a}$ is the mean flow velocity and $\alpha$ is the dispersivity. The Péclet number is defined as the ratio of the diffusion time over the domain $(L / 2 \pi)^{2} / D$ to the shear time $\gamma^{-1}, \mathrm{Pe}=\gamma L^{2} / 4 \pi^{2} D$. Mixing results in Figures 3 and 4 are shown as a function of a Péclet number based on the diffusion time over the initial plume width, $\mathrm{Pe}^{\prime}=\operatorname{Pe}\left(2 \pi s_{0} / L\right)^{2}$, since the mixing dynamics depends on the initial condition. While we consider transient transport in quasi-stationary flow, under the assumption that changes in flow occur over time scales larger than the characteristic transport times, the approach can be extended to nonstationary flows such as those described in Trauth and Fleckenstein (2017). This can be done by tracking Lagrangian particles numerically in unsteady flow simulations to measure stretching rates, as discussed in Meunier and Villermaux (2010). The effect of stretching on mixing can then be quantified in the same framework as described here. The effect of a background groundwater flow and prevalent upwelling/downwelling conditions may be studied similarly.

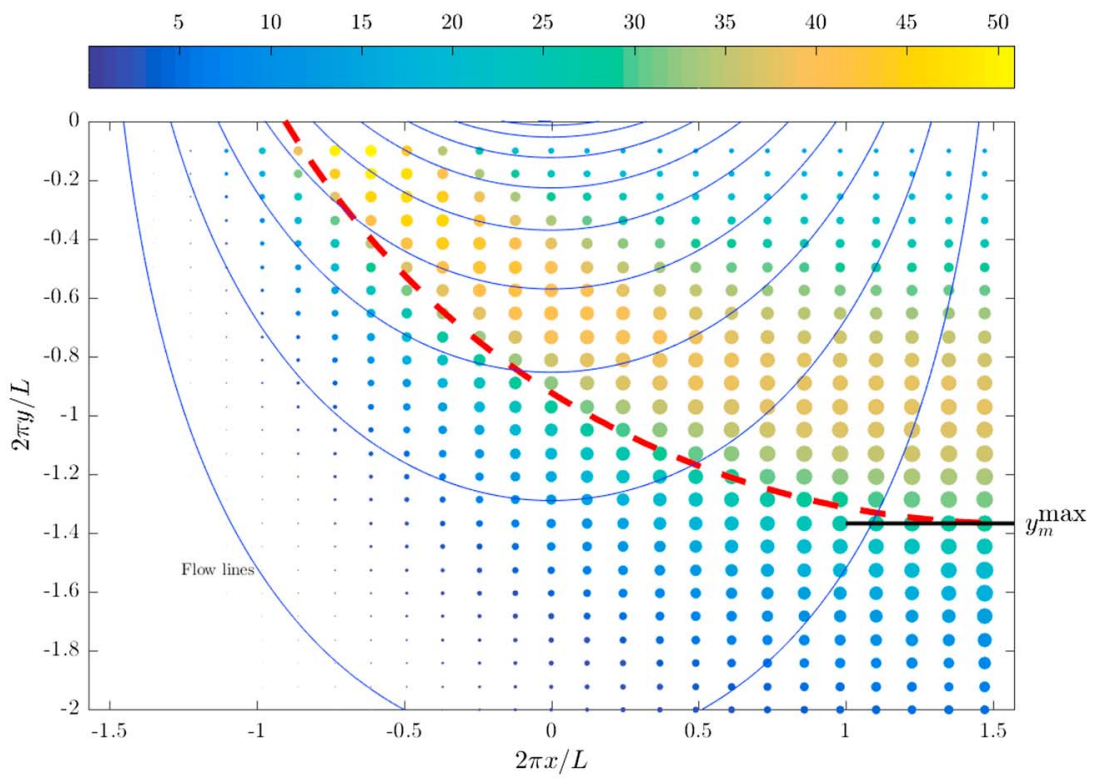

Figure 4. Map of the maximum and time-integrated mixing rates $\chi_{\max }$ and $\int \chi \mathrm{d} t$ at each point of the domain for $\operatorname{Pe}\left(s_{0} 2 \pi / L\right)^{2}=50$. The color of the marker depicts the integrated mixing rate. The size of the marker is proportional to the maximum mixing rate at that particular point. The dashed line depicts the location of the front at the mixing time, $\tau_{m}$. 


\subsection{Mixing Time}

The elongation of fluid elements by shear flows and the concomitant compression in the direction normal to the elongated plume (Le Borgne et al., 2015; Figure 1d) enhances concentration gradients by reducing the distance between different concentration levels. Simultaneously, diffusion tends to dissipate concentration gradients. The characteristic time at which these two effects balance is the mixing time $\tau_{m}$, estimated by equating the shear-induced compression and the diffusive broadening (Villermaux, 2012). For a shear flow following equation (8), the mixing time may be approximated as (see section S2 in supporting information)

$$
\tau_{m}=1 / \gamma\left(s_{0}^{2} \gamma / D\right)^{1 / 3}
$$

where $s_{0}$ is the initial plume width (Figure 1c). As discussed in the following section, the mixing time corresponds to maximum plume compression and therefore the concentration gradient. The mixing time decreases with the shear rate: A larger elongation rate implies a faster decrease of the plume width toward small scale where diffusion can overcome compression. Note that the mixing time is only defined when the stretching time $\gamma^{-1}$ is smaller than the diffusion time over the initial concentration gradient scale $s_{0}^{2} / D$. For vanishing $s_{0}$, the compression regime does not exist and concentration gradients decay monotonically in time.

\subsection{Mixing Rates}

The consequence of the stretching of a plume manifests as an acceleration of the mixing dynamics. Here we quantify the mixing rate from the scalar dissipation rate, which is proportional to the reaction rate for mixing-limited reactions (Le Borgne et al., 2010),

$$
\chi=\iint \mathrm{d} x \mathrm{~d} y D(\nabla c)^{2} .
$$

The scalar dissipation rates for a continuous and pulse injection, respectively, $\chi_{c}$ and $\chi_{p}$, derived from the lamella model (see section S3 in supporting information) are

$$
\begin{aligned}
& \chi_{p}=\sqrt{\frac{\pi}{2}} \frac{D I_{0} c_{0}^{2}}{s_{0}} \frac{(1+\gamma t)^{2}}{\left(1+\frac{4 D}{\gamma s_{0}^{2}}\left(\frac{(\gamma t)^{3}}{3}+(\gamma t)^{2}+\gamma t\right)\right)^{3 / 2}}, \\
& \chi_{c}=\frac{1}{\sqrt{2 \pi}} \frac{D I_{0} c_{0}^{2}}{s_{0}} \frac{(1+\gamma t)^{2}}{\sqrt{1+\frac{4 D}{\gamma s_{0}^{2}}\left(\frac{(\gamma t)^{3}}{3}+(\gamma t)^{2}+\gamma t\right)}},
\end{aligned}
$$

which are represented in a dimensionless form in Figure 3.

Considering first the pulse scenario, we distinguish two regimes as a function of Péclet number. For large Péclet numbers, the scalar dissipation increases initially as concentration gradients are enhanced by shear. Beyond the mixing time, diffusion overcomes compression and the concentration gradients decay as shown by the decrease of the scalar dissipation rate. The maximum mixing rate occurs at the mixing time, after which the maximum concentration starts decaying (inset of Figure 3a). For small Péclet numbers, the scalar dissipation rate decreases steadily in time as shear is not strong enough to overcome diffusion and compress the plume. For all Péclet numbers, the decay of the scalar dissipation rate is faster than in the absence of shear: $\chi_{p} \sim t^{-5 / 2}$ with shear compared to $\chi_{p} \sim t^{-3 / 2}$ in the absence of shear.

In the replacement scenario, the scalar dissipation rate follows the behavior observed for the pulse scenario until the mixing time. In contrast to the pulse scenario, after the mixing time, the scalar dissipation rate continues to grow steadily, but at a slower rate than before the mixing time, as concentration gradients are sustained by the continuous injection of new solutes and the mixing interface length continuous to increase. This growth obviously comes to an end when the front reaches the outlet of the domain. The asymptotic scaling of the scalar dissipation is $\chi_{c} \sim t^{1 / 2}$ with shear compared to $\chi_{c} \sim t^{-1 / 2}$ in the absence of shear.

\subsection{Formation of Transient Mixing Hot Spots}

The temporal evolution of the mixing rate observed in Figure 3 translates into an evolution with depth of these rate when converting the travel time of the plume in a position along the streamlines. For the pulse scenario, the mixing rate increases until the depth corresponding to that of the mixing time (Figure 4). Hence, while 
the mixing rate is expected to be maximal at the surface in the absence of shear, with shear it can be maximal at depth. To visualize this mixing hot spot, we convert the lamella scale maximum and time integrated mixing rates $\chi_{\max }$ and $\int \chi \mathrm{d}$ t, which are Lagrangian quantities attached to the plume, into their Eulerian counterparts. The latter are computed at different times by assigning the Lagrangian values to the places in the domain where the lamella traveling along each streamlines are located (Figure 4). This representation reveals the depth distribution of the transient mixing hot spot induced by shear.

As shown by the dashed line in Figure 4 the hot spot location is well delineated by the depth at which the mixing time $\tau_{m}$ is reached (see sections S1 and S2 in supporting information, equation with $t=\tau_{m}$ ):

$$
y_{m}=-\frac{L}{2 \pi} \ln \frac{\cos \left(\frac{2 \pi}{L} x_{0}-\frac{\tau_{m}}{\tau_{a}} \cos 2 \pi x_{0} / L\right)}{\cos 2 \pi x_{0} / L},
$$

which varies across streamlines (Figure 4). When the streamline injection location is close to $x=0$, the enhanced mixing rate occurs at much shallower depths as compared to injection locations close to the maximal hydraulic head. When taking the limit $2 \pi x_{0} / L \rightarrow \pi / 2$ in equation (14), the largest depth for hot spot formation is

$$
y_{m}^{\max }=-\frac{L}{2 \pi} \ln \left(1+\frac{\tau_{m}}{\tau_{a}}\right) .
$$

Using parameters estimated from past studies, the mixing hot spot depths are found to range from few centimeters for hyporheic zones to few kilometers for regional flow systems (see Table S2 in supporting information). Note that the formation of mixing hot spots depends on the initial size of the plume $s_{0}$. For infinitely small initial plume widths, the solute plume cannot be further compressed by shear and the maximum concentration gradient occurs at the surface.

\section{Conclusions}

Our findings show that subsurface streamline patterns induced by topographic relief and hydraulic head gradients at surface-subsurface boundaries act effectively as shear flows due to differential velocities of neighboring streamlines. Shear flows accelerate mixing dynamics within flow cells and induce transient mixing hot spots in the subsurface. The depth and intensity of such hot spots depend on the mixing time $\tau_{m}$, which we define as a function of hydraulic head gradient, permeability, dispersion coefficient, and characteristic initial plume width. The insights gained from the idealized solute transport scenarios may help understanding the impact of hydraulic head gradients at the surface-subsurface interface on a range of mixing processes. This includes in particular the transient dynamics of solute mixing and heat transfer in the hyporheic zone (Hester et al., 2017; Kaufman et al., 2017; Marzadri et al., 2013; Zheng \& Cardenas, 2018). Furthermore, acceleration of mixing rates by shear flows in hillslopes may influence the statistics of concentrations in rivers (e.g., Kirchner \& Neal, 2013; Shuai et al., 2017) and concentration-discharge relationships (e.g., Godsey et al., 2009; Neilson et al., 2018).

The approach presented here may be extended to quantify the consequences of mixing on biogeochemical reactions, such as redox reactions, dissolution reactions, and microbiological processes. In the case where reactions are triggered by the transient mixing processes between different solutes within a flow cell (Hester et al., 2017), the results derived here for mixing rates and mixing hot spots may be translated into reaction rates and reaction hot spots (supporting information de Simoni et al., 2005; Le Borgne et al., 2014). The combined effect of mixing and kinetic limitations in shear flows may be also considered following the approach of Bandopadhyay et al. (2017). In the case where reactions take place between a transported solute plume and the solid substrate, the results presented here would also likely affect reaction kinetics, which depend on the distribution of concentrations in the fluid phase. As the latter depend on the mixing rates, our results will likely impact the temporal dynamics and spatial distribution of reaction rates.

While we have focused on the impact of hydraulic head gradients alone, other important features influence mixing hot spot development, including variable saturation, permeability heterogeneity, biogeochemical heterogeneity, or nonstationary hydrological fluctuations. In particular, a key question that stems from this analysis is that of the relative importance of topography-induced shear versus heterogeneity-induced shear. Heterogeneity is expected to generate strong velocity gradients at small scale that should dominate the dynamics of mixing at early time. However, while heterogeneity should initially dissipate concentration gradients, the latter should be enhanced in a second stage by the larger-scale shear induced by topography, 


\section{Acknowledgments}

The authors gratefully acknowledge support from Agence Nationale de la Recherche through project ANR-14-CE04-0003-01 subsurface mixing and reaction. A. B. also acknowledges the Alexander von Humboldt Foundation for postdoctora fellowship. All the data are given in Tables S1 and S2. leading to a late time mixing dynamics equivalent to that described here. A detailed analysis of the respective effect of topography and heterogeneity on mixing is the subject of current investigations.

\section{References}

Bandopadhyay, A., Le Borgne, T., Méheust, Y., \& Dentz, M. (2017). Enhanced reaction kinetics and reactive mixing scale dynamics in mixing fronts under shear flow for arbitrary Damköhler numbers. Advances in Water Resources, 100, 78-95.

Bardini, L., Boano, F., Cardenas, M., Revelli, R., \& Ridolfi, L. (2012). Nutrient cycling in bedform induced hyporheic zones. Geochimica et Cosmochimica Acta, 84, 47-61.

Bartsch, S., Frei, S., Ruidisch, M., Shope, C. L., Peiffer, S., Kim, B., \& Fleckenstein, J. H. (2014). River-aquifer exchange fluxes under monsoonal climate conditions. Journal of Hydrology, 509, 601-614.

Boano, F., Revelli, R., \& Ridolfi, L. (2007). Bedform-induced hyporheic exchange with unsteady flows. Advances in Water Resources, 30(1), $148-156$

Briggs, M. A., Day-Lewis, F. D., Zarnetske, J. P., \& Harvey, J. W. (2015). A physical explanation for the development of redox microzones in hyporheic flow. Geophysical Research Letters, 42, 4402-4410. https://doi.org/10.1002/2015GL064200

Brunner, P., Therrien, R., Renard, P., Simmons, C. T., \& Hendricks Franssen, H.-J. (2017). Advances in understanding river-groundwater interactions. Reviews of Geophysics, 55, 818-854. https://doi.org/10.1002/2017RG000556

Cardenas, M. B. (2007). Potential contribution of topography-driven regional groundwater flow to fractal stream chemistry: Residence time distribution analysis of Tóth flow. Geophysical Research Letters, 34, L05403. https://doi.org/10.1029/2006GL029126

Cardenas, M. B. (2008). Surface water-groundwater interface geomorphology leads to scaling of residence times. Geophysical Research Letters, 35, L08402. https://doi.org/10.1029/2008GL033753

Chiogna, G., Hochstetler, D., Bellin, A., Kitanidis, P., \& Rolle, M. (2012). Mixing, entropy and reactive solute transport. Geophysical Research Letters, 30, L20405. https://doi.org/10.1029/2012GL053295

Cirpka, O. A., \& Kitanidis, P. K. (2000). Characterization of mixing and dilution in heterogeneous aquifers by means of local temporal moments. Water Resources Research, 36(5), 1221-1236.

Cirpka, O. A., Olsson, Å., Ju, Q., Rahman, M., \& Grathwohl, P. (2006). Determination of transverse dispersion coefficients from reactive plume lengths. Groundwater, 44(2), 212-221.

de Anna, P., Dentz, M., Tartakovsky, A., \& Le Borgne, T. (2014). The filamentary structure of mixing fronts and its control on reaction kinetics in porous media flows. Geophysical Research Letters, 41, 4586-4593. https://doi.org/10.1002/2014GL060068

de Anna, P., Jimenez-Martinez, J., Tabuteau, H., Turuban, R., Le Borgne, T., Derrien, M., \& Meheust, Y. (2014). Mixing and reaction kinetics in porous media: An experimental pore scale quantification. Environmental Science \& Technology, 48, 508-516.

de Barros, F., Dentz, M., Koch, J., \& Nowak, W. (2012). Flow topology and scalar mixing in spatially heterogeneous flow fields. Geophysical Research Letters, 39, L08404. https://doi.org/10.1029/2012GL051302

de Simoni, M., Carrera, J., Sanchez-Vila, X., \& Guadagnini, A. (2005). A procedure for the solution of multicomponent reactive transport problems. Water Resources Research, 41, W11410. https://doi.org/10.1029/2005WR004056

Elliott, A. H., \& Brooks, N. H. (1997). Transfer of nonsorbing solutes to a streambed with bed forms: Theory. Water Resources Research, 33(1), $123-136$.

Engdahl, N. B., Benson, D. A., \& Bolster, D. (2014). Predicting the enhancement of mixing-driven reactions in nonuniform flows using measures of flow topology. Physical Review E, 90(5), 51001

Eylers, H. (1994). Transport of adsorbing metal ions between stream water and sediment bed in a laboratory flume (Ph.D. thesis), California Institute of Technology.

Freeze, R. A., \& Witherspoon, P. A. (1966). Theoretical analysis of regional groundwater flow: 1. Analytical and numerical solutions to the mathematical model. Water Resources Research, 2(4), 641-656.

Freeze, R. A., \& Witherspoon, P. (1967). Theoretical analysis of regional groundwater flow: 2. Effect of water-table configuration and subsurface permeability variation. Water Resources Research, 3(2), 623-634.

Frei, S., Knorr, K. H., Peiffer, S., \& Fleckenstein, J. H. (2012). Surface micro-topography causes hot spots of biogeochemical activity in wetland systems: A virtual modeling experiment. Journal of Geophysical Research, 117, G00N12. https://doi.org/10.1029/2012JG002012

Godsey, S. E., Kirchner, J. W., \& Clow, D. W. (2009). Concentration-discharge relationships reflect chemostatic characteristics of us catchments. Hydrological Processes, 23(13), 1844-1864.

Gomez-Velez, J. D., Harvey, J. W., Cardenas, M. B., \& Kiel, B. (2015). Denitrification in the mississippi river network controlled by flow through river bedforms. Nature Geoscience, 8(12), $941-945$

Green, C. T., Böhlke, J. K., Bekins, B. A., \& Phillips, S. P. (2010). Mixing effects on apparent reaction rates and isotope fractionation during denitrification in a heterogeneous aquifer. Water Resources Research, 46, W08525. https://doi.org/10.1029/2009WR008903

Gu, C., Anderson, W., \& Maggi, F. (2012). Riparian biogeochemical hot moments induced by stream fluctuations. Water Resources Research, 48, W09546. https://doi.org/10.1029/2011WR011720

Harvey, J. W., \& Bencala, K. E. (1993). The effect of streambed topography on surface-subsurface water exchange in mountain catchments. Water Resources Research, 29(1), 89-98.

Hatch, C. E., Fisher, A. T., Revenaugh, J. S., Constantz, J., \& Ruehl, C. (2006). Quantifying surface water-groundwater interactions using time series analysis of streambed thermal records: Method development. Water Resources Research, 42, W10410. https://doi.org/10.1029/ 2005WR004787

Hester, E. T., Cardenas, M. B., Haggerty, R., \& Apte, S. V. (2017). The importance and challenge of hyporheic mixing. Water Resources Research, 53, 3565-3575. https://doi.org/10.1002/2016WR020005

Hester, E. T., Young, K. I., \& Widdowson, M. A. (2014). Controls on mixing-dependent denitrification in hyporheic zones induced by riverbed dunes: A steady state modeling study. Water Resources Research, 50, 9048-9066. https://doi.org/10.1002/2014WR015424

Holmes, R. M., Jones, J. B. Jr, Fisher, S. G., \& Grimm, N. B. (1996). Denitrification in a nitrogen-limited stream ecosystem. Biogeochemistry, $33(2), 125-146$

Jiang, X.-W., Wan, L., Cardenas, M. B., Ge, S., \& Wang, X.-S. (2010). Simultaneous rejuvenation and aging of groundwater in basins due to depth-decaying hydraulic conductivity and porosity. Geophysical Research Letters, 37, L05403. https://doi.org/10.1029/2010GL042387

Jiang, X.-W., Wang, X.-S., Wan, L., \& Ge, S. (2011). An analytical study on stagnation points in nested flow systems in basins with depth-decaying hydraulic conductivity. Water Resources Research, 47, W01512. https://doi.org/10.1029/2010WR009346

Jiménez-Martínez, J., de Anna, P., Tabuteau, H., Turuban, R., Borgne, T. L., \& Méheust, Y. (2015). Pore-scale mechanisms for the enhancement of mixing in unsaturated porous media and implications for chemical reactions. Geophysical Research Letters, 42, 5316-5324. https://doi.org/10.1002/2015GL064513 
Kaufman, M. H., Cardenas, M. B., Buttles, J., Kessler, A. J., \& Cook, P. L. (2017). Hyporheic hot moments: Dissolved oxygen dynamics in the hyporheic zone in response to surface flow perturbations. Water Resources Research, 53, 6642-6662. https://doi.org/10.1002/ 2016WR020296

Kirchner, J. W., Feng, X., \& Neal, C. (2000). Fractal stream chemistry and its implications for contaminant transport in catchments. Nature, 403(6769), 524-527.

Kirchner, J. W., \& Neal, C. (2013). Universal fractal scaling in stream chemistry and its implications for solute transport and water quality trend detection. Proceedings of the National Academy of Sciences, 110, 12,213-12,218.

Kitanidis, P. K. (1994). The concept of the dilution index. Water Resources Research, 30(7), 2011-2026.

Kooi, H. (2016). Groundwater flow as a cooling agent of the continental lithosphere. Nature Geoscience, 9(3), 227-230.

Le Borgne, T., Dentz, M., Bolster, D., Carrera, J., De Dreuzy, J.-R., \& Davy, P. (2010). Non-Fickian mixing: Temporal evolution of the scalar dissipation rate in heterogeneous porous media. Advances in Water Resources, 33(12), 1468-1475.

Le Borgne, T., Dentz, M., \& Villermaux, E. (2013). Stretching, coalescence and mixing in porous media. Physical Review Letters, $110(204), 501$.

Le Borgne, T., Dentz, M., \& Villermaux, E. (2015). The lamellar description of mixing in porous media. Journal of Fluid Mechanics, 770, 458-498.

Le Borgne, T., Ginn, T. R., \& Dentz, M. (2014). Impact of fluid deformation on mixing-induced chemical reactions in heterogeneous flows. Geophysical Research Letters, 41, 7898-7906. https://doi.org/10.1002/2014GL062038

Li, L., Maher, K., Navarre-Sitchler, A., Druhan, J., Meile, C., Lawrence, C., et al. (2017). Expanding the role of reactive transport models in critical zone processes. Earth-Science Reviews, 165, 280-301.

Maher, K., \& Chamberlain, C. (2014). Hydrologic regulation of chemical weathering and the geologic carbon cycle. Science, 343(6178), $1502-1504$.

Maier, H. S., \& Howard, K. W. (2011). Influence of oscillating flow on hyporheic zone development. Groundwater, 49(6), 830-844.

Malzone, J. M., Lowry, C. S., \& Ward, A. S. (2016). Response of the hyporheic zone to transient groundwater fluctuations on the annual and storm event time scales. Water Resources Research, 52, 5301-5321. https://doi.org/10.1002/2015WR018056

Marzadri, A., Tonina, D., \& Bellin, A. (2013). Effects of stream morphodynamics on hyporheic zone thermal regime. Water Resources Research, 49, 2287-2302. https://doi.org/10.1002/wrcr.20199

Meunier, P., \& Villermaux, E. (2010). The diffusive strip method for scalar mixing in two dimensions. Journal of Fluid Mechanics, 662, 134-172.

Naranjo, R. C., Niswonger, R. G., \& Davis, C. J. (2015). Mixing effects on nitrogen and oxygen concentrations and the relationship to mean residence time in a hyporheic zone of a riffle-pool sequence. Water Resources Research, 51, 7202-7217. https://doi.org/10.1002/ 2014WR016593

Neilson, B. T., Cardenas, M. B., O'Connor, M. T., Rasmussen, M. T., King, T. V., \& Kling, G. W. (2018). Groundwater flow and exchange across the land surface explain carbon export patterns in continuous permafrost watersheds. Geophysical Research Letters, 45, 7596-7605. https://doi.org/10.1029/2018GL078140

Ottino, J. M. (1989). The Kinematics of Mixing: Stretching, Chaos, and Transport (Vol. 3). New York: Cambridge University Press.

Paster, A., Aquino, T., \& Bolster, D. (2015). Incomplete mixing and reactions in laminar shear flow. Physical Review E, 92(1), 12922.

Ranz, W. E. (1979). Applications of a stretch model to mixing, diffusion, and reaction in laminar and turbulent flows. AlChE Journal, 25(1), $41-47$.

Reeve, A., Siegel, D., \& Glaser, P. (2000). Simulating vertical flow in large peatlands. Journal of Hydrology, 227(1), $207-217$.

Rolle, M., Eberhardt, C., Chiogna, G., Cirpka, O. A., \& Grathwohl, P. (2009). Enhancement of dilution and transverse reactive mixing in porous media: Experiments and model-based interpretation. Journal of Contaminant Hydrology, 110(3), 130-142.

Savant, S. A., Reible, D. D., \& Thibodeaux, L. J. (1987). Convective transport within stable river sediments. Water Resources Research, 23(9), $1763-1768$

Schmadel, N. M., Ward, A. S., Lowry, C. S., \& Malzone, J. M. (2016). Hyporheic exchange controlled by dynamic hydrologic boundary conditions. Geophysical Research Letters, 43, 4408-4417. https://doi.org/10.1002/2016GL068286

Shuai, P., Cardenas, M. B., Knappett, P. S., Bennett, P. C., \& Neilson, B. T. (2017). Denitrification in the banks of fluctuating rivers: The effects of river stage amplitude, sediment hydraulic conductivity and dispersivity, and ambient groundwater flow. Water Resources Research, 53, 7951-7967. https://doi.org/10.1002/2017WR020610

Song, X., Chen, X., Stegen, J., Hammond, G., Song, H.-S., Dai, H., et al. (2018). Drought conditions maximize the impact of high-frequency flow variations on thermal regimes and biogeochemical function in the hyporheic zone. Water Resources Research. 54. https://doi.org/10.1029/2018WR022586

Stallman, R. (1965). Steady one-dimensional fluid flow in a semi-infinite porous medium with sinusoidal surface temperature. Journal of Geophysical Research, 70(12), 2821-2827.

Toth, J. (1963). A theoretical analysis of groundwater flow in small drainage basins. Journal of Geophysical Research, 68(16), 4795-4812. Tóth, J. (2009). Gravitational Systems of Groundwater Flow: Theory, Evaluation, Utilization. New York: Cambridge University Press.

Trauth, N., \& Fleckenstein, J. H. (2017). Single discharge events increase reactive efficiency of the hyporheic zone. Water Resources Research, 53, 779-798. https://doi.org/10.1002/2016WR019488

Trauth, N., Schmidt, C., Vieweg, M., Maier, U., \& Fleckenstein, J. H. (2014). Hyporheic transport and biogeochemical reactions in pool-riffle systems under varying ambient groundwater flow conditions. Journal of Geophysical Research: Biogeosciences, 119, 910-928. https://doi.org/10.1002/2013JG002586

Vaccaro, J., \& Bolke, E. (1983). Evaluation of water-quality characteristics of part of the spokane aquifer, washington and idaho using a solute-transport digital model (Tech. rep.). Tacoma, WA: US Geological Survey.

Villermaux, E. (2012). Mixing by porous media. Comptes Rendus Mé,canique, 340(11), 933-943.

Zarnetske, J. P., Haggerty, R., Wondzell, S. M., Bokil, V. A., \& González-Pinzón, R. (2012). Coupled transport and reaction kinetics control the nitrate source-sink function of hyporheic zones. Water Resources Research, 48, W11508. https://doi.org/10.1029/2012WR011894

Zheng, L., \& Cardenas, M. B. (2018). Diel stream temperature effects on nitrogen cycling in hyporheic zones. Journal of Geophysical Research: Biogeosciences, 123. https://doi.org/10.1029/2018JG004412

Zlotnik, V. A., Cardenas, M. B., \& Toundykov, D. (2011). Effects of multiscale anisotropy on basin and hyporheic groundwater flow. Groundwater, 49(4), 576-583. 